\title{
Erratum to: Meiotically asynapsis-induced aneuploidy in autopolyploid Arabidopsis thaliana
}

\author{
Fang Wei - Gai-Sheng Zhang
}

Published online: 13 January 2010

(C) The Botanical Society of Japan and Springer 2010

\section{Erratum to: J Plant Res}

DOI 10.1007/s10265-009-0262-4

By mistake, the micrograph for Fig. 1e was also used for Fig. 5e. The correct micrograph for Fig. 5e is shown below.

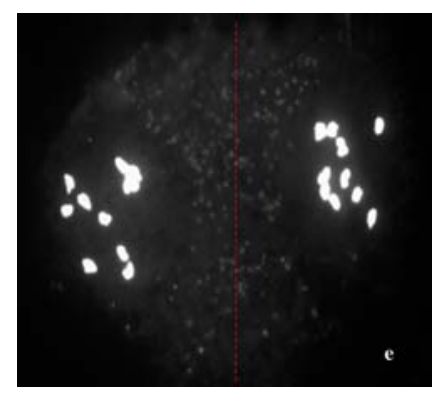

The online version of the original article can be found under doi: 10.1007/s10265-009-0262-4.

F. Wei · G.-S. Zhang ( $\bowtie)$

College of Agronomy, Northwest A\&F University,

Xinong Road 22, Yangling 712100, Shaanxi,

People's Republic of China

e-mail: zhanggsh@public.xa.sn.cn
An erroneous description was given in the third paragraph of the section "Analysis of aneuploidy transmission in tetraploid asyl" under "Results". The second sentence of this paragraph should read:

Chromosome counting indicated that about $90 \%$ of the backcrossed seeds analyzed have an increased or reduced number of chromosomes when tetraploid asyl was the pollen recipient, and about half of these seeds show a gain of chromosomes. 